\title{
Erratum to: Parthood and naturalness
}

\author{
M. Eddon ${ }^{1}$
}

Published online: 15 June 2017

(C) Springer Science+Business Media B.V. 2017

\section{Erratum to: Philos Stud DOI 10.1007/s11098-016-0852-7}

In the original publication of the article in the section, "Perfect naturalness and supervenience," the third paragraph that reads as: "Let $\phi \phi$ be a set...supervenience:" should read as: "Let $\phi$ be a set of properties and relations. Let a $\phi$ preserving isomorphism be a bijective function $f$ from the domain of $w_{1}$ to the domain of $w_{2}$ such that for any $\left\langle x_{1}, \ldots, x_{n}\right\rangle$ in $w_{1}$ and any $n$-place property or relation $R$ in $\phi,\left\langle x_{1}, \ldots, x_{n}\right\rangle$ instantiate $R$ iff $\left\langle f\left(\mathrm{x}_{1}\right), \ldots, f\left(x_{n}\right)\right\rangle$ in $w_{2}$ instantiate $R$. Now consider the following three notions of global supervenience."

The sentence in the last paragraph under the section "Background" that reads as: "I do not...harmless." should read as: "I do not assume that for any region $\mathrm{R}$ that is a sub-region of $\mathrm{R}^{\prime}, \mathrm{R}$ is a part of $\mathrm{R}^{\prime}$, though that assumption is harmless."

The following reference was missed out in the original publication.

\section{Reference}

Thomson, J. J. (1998). The statue and the clay. Nous, 32, 149-174.

The online version of the original article can be found under doi:10.1007/s11098-016-0852-7.

The original article was corrected.

M. Eddon

mayae@philos.umass.edu

1 University of Massachusetts-Amherst, Amherst, MA, USA 